\title{
Artelogie
}

artelogie Recherche sur les arts, le patrimoine et la littérature de I'Amérique latine

$11 \mid 2017$

Délocalités, translocalités et activisme dans l'art électronique et biomédiale latino-américain

\section{La literatura electrónica latinoamericana, caribeña y global: generaciones, fases y tradiciones}

Leonardo Flores

\section{OpenEdition}

1 Journals

Edición electrónica

URL: http://journals.openedition.org/artelogie/1590

DOI: 10.4000/artelogie. 1590

ISSN: 2115-6395

Editor

Association ESCAL

Referencia electrónica

Leonardo Flores, «La literatura electrónica latinoamericana, caribeña y global: generaciones, fases y tradiciones », Artelogie [En línea], 11 | 2017, Publicado el 28 diciembre 2017, consultado el 03 mayo 2019. URL : http://journals.openedition.org/artelogie/1590; DOI : 10.4000/artelogie.1590

Este documento fue generado automáticamente el 3 mayo 2019.

Association ESCAL 


\title{
La literatura electrónica
}

\section{latinoamericana, caribeña y global: generaciones, fases y tradiciones}

\author{
Leonardo Flores
}

1 En su nombramiento reciente como editora de obras creativas para la revista de literatura caribeña SX Salon, la poeta Rosamond S. King publicó su "statement on digital literature" haciendo un llamado para recibir obras de literatura digital caribeña, definiéndola así:

And what might Caribbean digital literature be? I hope we will discover that together, but it could be described as literature for which a digital or electronic component or aspect is integral to both the structure and the meaning of the piece. (http://smallaxe.net/sxsalon/poetry-prose/statement-digitalliterature)

2 Encuentro dos detalles interesantes acerca de su llamado y definición. El primero es que reconoce que es algo que iremos descubriendo sobre la marcha. El segundo es que según elabora la definición no define la literatura caribeña. Esto no es una crítica -no es necesario reiterar lo que se vuelve obvio en una revista que lleva años publicando literatura caribeña- pero lo menciono para recalcar algo que usualmente se presume cuando se definen las literaturas electrónicas nacionales: que la literatura electrónica se puede simplemente añadir a las tradiciones literarias nacionales y regionales.

$3 \quad$ ¿Y por qué no? Estas tradiciones literarias tienen sus historiales, vertientes y cánones a las cuales se les pueden sumar las experimentaciones recientes que surgen en conversación con las tecnologías digitales. Las narrativas de continuidad son más reconfortantes que las de ruptura y aún las revoluciones literarias suelen incorporarse retrospectivamente como momentos de cambio e innovación dentro de movimientos más amplios.

4 ¿Pero qué tal si las tecnologías digitales traen un cambio de paradigma tan radical y tan ajeno a los movimientos literarios tradicionales que se puede considerar como un movimiento internacional y hasta posnacional? ¿Qué tal si la literatura electrónica sucede a pesar de las literaturas nacionales? Parte de la razón para esta ruptura es que las 
tradiciones literarias históricamente han sido basadas en las tecnologías de escritura en papel y su adopción cultural está atada a nivel social y de mercado. En comparación, las tecnologías digitales tienen poco tiempo de desarrollo y las literaturas que potencian aún se encuentran en su infancia.

5 En este ensayo cuestiono narrativas de tradiciones literarias nacionales y regionales cuando se refieren a la literatura electrónica con el fin de mostrar cómo la misma está atada primordialmente a tecnologías digitales e influencias internacionales. Contextualizaré esto con un modelo de las fases de desarrollo de la literatura electrónica, situando la literatura electrónica latinoamericana y caribeña dentro del mismo, según observable en este momento.

6 Antes de presentar el modelo, conviene presentar un breve historial de la literatura electrónica. En su influyente ensayo "Print is flat: code is deep: the importance of mediaspecific analysis", N. Katherine Hayles (2004) describió dos generaciones de literatura electrónica. La primera generación, centrada en los años 80 , estaba fuertemente ligada al modelo de la página y consistía principalmente de textos conectados hipertextualmente. El lanzamiento del World Wide Web en 1995 marca el comienzo de la segunda generación utilizaba más objetos multimedia: imágenes, animaciones, sonidos y eventos programados (86). Christopher Funkhouser (2007) expande y complica el historial de literatura digital establecido por Hayles con su libro Prehistoric Digital Poetry: An Archaeology of Forms 1959-1995. Este libro explora obras multimedia antes de la Web, y elabora un historial de obras generativas, muchas de las cuales se publicaban en medios impresos.

7 Para construir sobre este cimiento histórico, propongo una revisión en la cual se expande la primera generación descrita por Hayles para incluir toda obra creada antes de la Web, incluyendo géneros como hipertexto, obra generativa, ficción interactiva, videopoesía y obras multimedia creadas con programación y distribuídas en medios físicos: papel impreso, disco, videocassette, CD-ROM y los comienzos de obras en redes digitales, como Uncle Roger por Judy Malloy (1986), la cual se presentó como un performance a través de la red de Internet privada Art Com Electronic Network (ACEN) en The WELL.

8 La segunda generación de literatura electrónica surge a partir del comienzo y popularización de la Web en 1995 y se caracteriza por obras multimedia e interactivas diseñadas para distribución y recepción a través de medios digitales. Esto incluye obras creadas en HTML, JavaScript, CSS, Director, Flash y otros lenguajes de programación y programas de autoría multimedia. La mayoría de las obras de literatura electrónica contemporánea pueden ser categorizadas como pertenecientes a esta segunda generación.

9 Propongo que una tercera generación de literatura electrónica está construida sobre plataformas comerciales como tabletas y teléfonos inteligentes, recursos digitales que ofrecen conexiones via API (Application Programming Interface) y medios sociales como Facebook y Twitter. Los autores de esta tercera generación aprovechan los servicios e interfaces elaborados para las plataformas- como los vocabularios hápticos de las pantallas táctiles y las herramientas para interacción que ofrecen los Apps y medios sociales- para guiar las interacciones de sus lectoras. Estas interfaces familiares serán claves para la adopción masiva de la literatura electrónica, según veremos en mi modelo.

10 La tabla a continuación muestra ejemplos de tecnologías y obras en estas tres generaciones. 


\begin{tabular}{|c|c|c|}
\hline & e Herramientas & Ejemplos de obras \\
\hline $\begin{array}{l}\text { 1era } \\
\text { generación }\end{array}$ & $\begin{array}{l}\text { Programas de autoría } \\
\text { (Hypercard, Storyspace, INFORM, } \\
\text { etc.), herramientas de edición de } \\
\text { imágenes, audio y video, } \\
\text { Lenguajes de programación } \\
\text { (BASIC, UNIX, LISP, PASCAL, } \\
\text { FORTRAN, etc.) }\end{array}$ & $\begin{array}{l}\text { "Love Letter Generator" por Christopher } \\
\text { Strachey (1952), "ELIZA" por Joseph } \\
\text { Weizenstein (1964), "Roda Lume" por E. M. de } \\
\text { Melo e Castro (1969), "Nao" por Eduardo Kac } \\
\text { (1982), "First Screening" por bpNichol (1984), } \\
\text { "Uncle Roger" por Judy Malloy (1986), } \\
\text { "Amour" por Philippe Bootz (1989), } \\
\text { "afternoon, a story" por Michael Joyce (1987) y } \\
\text { "Marble Springs" por Deena Larsen (1993), } \\
\text { entre otros. }\end{array}$ \\
\hline $\begin{array}{l}\text { 2da } \\
\text { generación }\end{array}$ & $\begin{array}{l}\text { Lenguajes de markup y } \\
\text { programación para navegadores } \\
\text { Web (HTML, JavaScript, CSS, } \\
\text { DHTML), programas de autoría ( } \\
\text { Director, Flash, Java Applets, } \\
\text { etc.), formatos digitales (GIF } \\
\text { animado) }\end{array}$ & $\begin{array}{l}\text { "Anipoemas" por Ana María Uribe (1997), } \\
\text { "Enigma n" por Jim Andrews (1997), "White- } \\
\text { Faced Bromeliads on } 20 \text { Hectares" por Loss } \\
\text { Pequeño Glazier (1999), "The Struggle } \\
\text { Continues" por Young-Hae Chang Heavy } \\
\text { Industries (1999), Radikal Karaoke" por Belén } \\
\text { Gache (Taroko Gorge" por Nick Montfort } \\
\text { (2009), y "All the Delicate Duplicates" por Mez } \\
\text { y Andy Campbell (2016), entre otros. }\end{array}$ \\
\hline $\begin{array}{l}\text { 3ra } \\
\text { generación }\end{array}$ & $\begin{array}{l}\text { HTML5, CSS, JavaScript, } \\
\text { bibliotecas (JQuery, Tracery, etc.), } \\
\text { redes sociales (Facebook, Twitter, } \\
\text { Vine, Instagram, Snapchat, etc.), } \\
\text { plataformas móviles y para apps } \\
\text { (iOS, Android, etc.), servicios } \\
\text { mediante API (Wikipedia, } \\
\begin{array}{llr}\text { WikiHow, Wordnik, redes } \\
\text { sociales, etc.) }\end{array}\end{array}$ & $\begin{array}{l}\text { "Pentametron" por Ranjit Bhatnagar (2012), } \\
\text { "Poetuitéame" por Karen Villeda y Denise } \\
\text { Audirac (2014), "The Hunt for the Gay Planet" } \\
\text { por Anna Anthropy (2013), "Being } \\
\text { @SpencerPratt" por Mark C. Marino y Rob } \\
\text { Wittig (2013), "El 27" por Eugenio Tisselli } \\
\text { (2013) y "Pry" por Samantha Gorman y Danny } \\
\text { Cannizzaro (2015), }\end{array}$ \\
\hline
\end{tabular}

\section{Fases de adopción para la literatura electrónica}

11 El siguiente modelo identifica cuatro fases para la adopción social de la literatura electrónica: (1) acercamiento, (2) descubrimiento, (3) desarrollo y (4) adopción. Diversos países y regiones del mundo se encuentran en fases distinta y no homogéneamente, ya que diversas comunidades y demografías están en distintas fases de adopción. Las fases de adopción no corresponden directamente a las generaciones descritas arriba, según presentaré a continuación.

\section{Primera fase: acercamiento}

12 Las culturas hacen su acercamiento a la literatura electrónica cuando su producción cultural comienza a crear obras y formatos que se pueden realizar mejor en medios electrónicos o digitales. 
13 Por ejemplo el acercamiento al hipertexto, la literatura generativa- o sea, la literatura que utiliza distintos mecanismos para generar textos- y la cultura del remix tomó impulso a mediados del siglo XX con obras como Ficciones (1944) en la cual Jorge Luis Borges imagina laberintos de decisiones, bibliotecas combinatorias infinitas y versiones nuevas de obras que aunque parezcan ser plagiadas palabra por palabra exceden los méritos de la obra original. Para este tiempo, Vannebar Bush (1945) publicó un ensayo en el cual imaginó una máquina para hacer navegación y composición hipertextual utilizando tecnologías de microficha. Julio Cortázar (1963) con Rayuela ofrece una obra que requiere la toma de decisiones por parte de la lectora, creando una novela hipertextual. Raymond Queneau (1963) publicó un libro titulado Cent mille milliards de poèmes que con sus 10 páginas de sonetos con cada verso cortado como una página individual permite la generación de $10^{14}$ poemas: haciéndola una obra tanto hipertextual como generativa. El acercamiento al hipertexto alcanzó su auge en el mundo angloparlante con la popularización de los Mad Libs en 1953 y la serie de libros Choose your own adventures a partir de 1976. Los Mad Libs ofrecen plantillas de oraciones con palabras en blanco para que los lectores/escritores puedan completarlas para crear textos jocosos y sorprendentes. Los libros Choose your own adventures ofrecen decisiones para los lectores y cada libro ofrece decenas de narrativas potenciales y cientos de finales. Todo esto, y más, prepara a las culturas para géneros de literatura electrónica de la primera y segunda generación.

14 La multimodalidad en la literatura electrónica tiene acercamientos literarios en la poesía concreta y visual. Lamentablemente, algunos acercamientos son seguidos por distanciamientos. El ejemplo más claro es el de la literatura infantil y juvenil en la cual los libros son obras multimedia e interactivas al estar llenos de imágenes, texturas, cosas que se pueden halar para crear movimiento, y hasta pequeñas pieza electrónicas para añadir sonido a una página. Cuando uno aprende a leer, lo hace con obras multimodales e interactivas -un acercamiento a la tercera generación de literatura electrónica. Lamentablemente los sistemas educativos crean una ruptura al transicionar desde estos libros a libros ilustrados y luego a libros puramente textuales. Al llegar a la adultez, ya se han creado hábitos de escritura más propicios al libro tradicional y se ha perdido la oportunidad de desarrollar la creatividad en la escritura multimodal. El cómic es uno de los géneros multimodales que llega a la adultez aunque la creación de los mismos no suele ser parte de los currículos educativos. Con la Web, se vuelve a ser multimodal y aquí es que algunas personas rompen con la tradición del libro para escribir literatura electrónica.

15 Los acercamientos a la tercera generación de literatura electrónica suceden en géneros populares en los medios sociales: los memes, videos de líricas y tipografía cinética. Cuando millones de personas se expresan habitualmente creando y compartiendo memes hacen un acercamiento muy importante: están echando a un lado la página en blanco para escribir breve y poderosamente sobre imágenes. Cuando miles de personas utilizan programas como Adobe After Effects para crear videos donde las palabras de una canción o monólogo tienen animaciones sofisticadas que enfatizan lo que están diciendo, se crean los videos de líricas y la tipografía cinética. Ya no están escribiendo meramente palabras estáticas en un espacio, sino escriben palabras animadas sobre tiempo y espacio... y lo hacen con herramientas digitales. Estos no son casos de literatura electrónica como tal, pero están a un paso de ponerse a crear poesía o narrativas originales con este tipo de técnicas. 
16 Y estos acercamientos preparan a la gente para aprovechar las capacidades que ofrecen los medios digitales.

\section{Segunda fase: descubrimiento}

17 La literatura electrónica nace cuando una persona o grupo de personas descubren el potencial que ofrecen los medios digitales para crear obras literarias. El primer caso que conozco es el de Christopher Strachey quien utilizó la computadora Ferranti Mark I en la Universidad de Manchester en Gran Bretaña para programar un generador de cartas de amor en 1952. Pero todos los días alguien en el mundo despierta al potencial de la literatura electrónica, particularmente si ya han hecho el acercamiento y/o poseen las destrezas necesarias para aprovechar este potencial. Y esto lleva a la experimentación.

18 Cuando uno examina la obra completa de escritores de literatura electrónica, se puede observar que sus primeras obras son experimentos en las posibilidades de los medios digitales. En estas obras iniciales abundan las pruebas de conceptos con los cuales buscan encontrar su estilo y voz. Con frecuencia las obras son metatextuales, autorreflexivas, juguetonas y buscan capturar la atención del lector. Cada una de estas obras iniciales inventa sus estructuras y formas desde cero, de la misma forma en que el verso libre bien hecho crea la forma que necesita el poema. Esta fase está llena de interfaces nuevas, usualmente acompañadas de instrucciones, tutoriales y otros paratextos para guiar a lectores que tienen que adiestrarse en cómo interactuar con cada obra.

19 En América latina, algunos ejemplos de obras en esta fase son los Tipoemas y Anipoemas de Ana María Uribe (1997) que muestran la migración de la poeta del concretismo tipográfico a escribir letras en movimiento utilizando GIF animados, audio y animaciones en Flash. Estas obras iniciales son minimalistas y frecuentemente exploran distintos aspectos del mismo concepto, como hace con las sirenas en cardumen, los centauros en manada y las secuencias de letras haciendo gimnasia. Un ejemplo más reciente se ve con la obra Wordtoys por Belén Gache (2006) la cual utiliza tecnologías como Flash y Java para crear una serie de 14 obras cortas organizadas en una interfaz de libro. La familiaridad del libro como método para navegar de una obra a la otra -hay que voltear las páginas virtualessirve de puente para que lectores habituados al libro sepan qué hacer. Las obras mismas son breves, sencillas y variadas en sus conceptos, invitando a sus lectores a explorar las interfaces de cada obra.

20 Cuando se explora la obra completa de un escritor de literatura electrónica o de un colectivo artístico, se nota cómo el artista trasciende esta fase exploratoria inicial para encontrar su vocabulario digital, voz artística y relación con los lectores, llegando a la próxima fase.

\section{Tercera fase: desarrollo}

21 Esta fase lleva a la maduración de la literatura electrónica, no solo en la obra de cada artista, sino en la formación de géneros digitales, la creación de comunidades y la publicación de crítica literaria enfocada en la literatura electrónica.

22 Los cambios tan rápidos en las tecnologías digitales invitan siempre a la experimentación continua de los escritores de literatura electrónica, pero según crecen como artistas, se van enfocando en ciertas tecnologías, técnicas, interfaces y estructuras para sus obras. El 
dúo Young Hae Chang Heavy Industries (http://www.yhchang.com/) ha estado creando videopoesía por casi 20 años donde escriben narrativas y poemas cinemáticos sobre música. Y aunque sus videopoemas han evolucionado en técnicas visuales y su uso de música, lo han hecho dentro de un estilo y concepto visual distintivo. Han exhibido su obra en museos y galerías alrededor del mundo y aunque aún la producen utilizando Flash, ahora en vez de publicarla en el formato obsoleto de Flash para la Web, los publican como videos en YouTube y en su página Web.

23 La obsolescencia de plataformas digitales, como Shockwave y Flash, también motiva a escritores a migrar y descubrir nuevos formatos. Un ejemplo idóneo de este fenómeno es el escritor estadounidense Alan Bigelow (http://webyarns.com/) quien dedicó su primera década utilizando Flash y desarrollando un estilo distintivo para sus obras y luego tuvo que migrar a CSS, HTML5 y JavaScript para crear una nueva estructura para sus narrativas. Bigelow y otros también adoptan las interfaces que ofrecen sistemas como iOS y Android para que los usuarios ya conozcan el lenguaje de interacción con los equipos.

24 Más allá de los artistas individuales, los géneros literarios digitales van tomando forma con el paso del tiempo. A grandes rasgos, estos son los géneros más desarrollados en la literatura electrónica: literatura generativa, bots, literatura cinética, videojuegos, hipertextos, obras multimodales, poesía en código, net.art, performance, instalaciones digitales, realidad virtual, realidad aumentada y obras móviles. En mi columna de literatura electrónica para la revista 80 Grados, describo estos géneros en detalle (Flores 2016, 2017). Algunos de estos géneros digitales tienen décadas de desarrollo con cientos y hasta miles de obras. Otros géneros y subgéneros han formado comunidades, organizaciones, competencias y premios.

25 La formación de comunidades, tanto artísticas como académicas es otro indicador de que algún país o región se encuentra en la tercera fase. La Electronic Literature Organization (ELO) recién cumplió 20 años de ser fundada y en estas dos décadas ha crecido de un grupo pequeño en los Estados Unidos a ser una organización internacional con miembros alrededor del planeta. La ELO ofrece una conferencia y festival anual y ha publicado tres colecciones de literatura electrónica. La Red de Literatura Electrónica Latinoamericana (litElat) fue fundada en el 2015 tras la conferencia E-Poetry 2015 en Buenos Aires y ha logrado conectar artistas, académicos y colectivos de distintas partes de Latinoamérica y el Caribe. La importancia de este tipo de comunidades es que sus actividades ayudan a levantar la literatura electrónica hacia nuevos niveles de colaboración, sofisticación y diseminación.

26 La publicación de artículos, libros, blogs y bases de datos de historia, crítica y teorías de la literatura digital es otro indicador de desarrollo. La diseminación en universidades y hacia el público general ayuda a educar a nuevas generaciones a leer y crear literatura electrónica, preparando el terreno para la cuarta fase.

\section{Cuarta fase: adopción}

Hasta el momento, ningún país ni región ha logrado que se adopte masivamente la literatura electrónica ni ha logrado establecer mercados para la misma. Actualmente, son muy pocos los autores de este género literario que pueden vivir de la venta de sus creaciones. Para lograr esto, hay que aumentar exponencialmente la audiencia a niveles comparables con la literatura tradicional. Esto requiere adiestrar a nuevas audiencias con las destrezas que necesitan para leer, apreciar y crear estas obras. 
28 La educación es clave para lograr esta meta. Para alcanzarla es necesario incorporar la literatura electrónica los currículos de educación general universitaria y escolar. Además, las nuevas generaciones necesitan desarrollar sus destrezas de programación de computadoras, composición multimodal, retórica digital y ética para las redes. La literatura electrónica puede ser como los videojuegos, los cuales alcanzaron adopción masiva en pocas décadas y han creado un mercado tan lucrativo como el cine.

29 La literatura electrónica está acercándose a la cuarta fase en Europa y los Estados Unidos. Por ejemplo el portal de literatura electrónica de Jason Nelson (http:// secrettechnology.com) ganó un premio Webby en el 2009. Hay obras en Twine y bots en Twitter que tienen cientos de miles de lectores y seguidores. Y la influencia y alcance de las mismas se extiende alrededor del mundo a través de las redes digitales.

30 Las casas editoras poco a poco van trascendiendo el formato del e-book, el cual simplemente representa el libro en los medios digitales pero que presenta poca innovación. La literatura infantil y juvenil digital va abriéndose camino en los mercados y llegando a audiencias que cada vez más leerán en pantallas en vez de libros. Se acerca el día en que la literatura electrónica se adopte masivamente, tal vez hasta el punto en que simplemente se conocerá como literatura.

\section{Las tecnologías de la palabra y las literaturas nacionales}

31 Las obras más antiguas de los idiomas modernos son los poemas épicos en que se narraban las historias de los héroes que de cierta forma fundaban sus naciones: Beowulf para los anglo-sajones, El cantar del Mío Cid para los españoles, Le chanson de Roland para los franceses, Orlando Furioso para los italianos, etc. Estas historias circulaban con los bardos que las cantaban de lugar en lugar y sobrevivían el pasar del tiempo en las mentes del pueblo, gracias en parte a una tecnología que permitía que se recordaran: la poesía.

32 Según las teorías de Walter J. Ong (2013) plasmadas en su libro Orality and Literacy: The Technologizing of the Word, las oralidad describe el funcionamiento de culturas que aún no han descubierto o implantado la alfabetización masiva- el saber leer y escribir. Para poder almacenar y transmitir el conocimiento a través de memoria colectiva, las culturas orales necesitan darle forma memorable, utilizando elementos poéticos como versos, estrofas, rima, ritmo, aliteración, listados, imágenes recurrentes y metáforas, entre otros. Ong explica que aun cuando la escritura toma el rol de servir de memoria para las sociedades, siempre se conservan tradiciones de la oralidad: refranes, música popular improvisatoria como la trova, el rap, el soneo en la salsa y otros ejemplos.

33 Las literaturas nacionales y regionales encuentran sus orígenes en estas tradiciones orales las cuales se diseminan regionalmente entre comunidades y sociedades que tienen contacto mercantil y cultural. En el contexto latinoamericano y caribeño, las culturas que invadieron y colonizaron territorios llevaron sus idiomas y cultura en forma oral y escrita al llamado "nuevo mundo" y las pusieron en contacto con las culturas nativas -también con sus tradiciones orales. El tráfico de esclavos desde África también añadió la música, cantos, creencias y cultura oral oriunda de ese continente a la mezcla cultural de los países que no tenían poblaciones indígenas cuantiosas para esclavizar. La composición demográfica particular de cada área o isla caribeña y la mezcla de las mismas al pasar de 
los siglos fue el comienzo de las sociedades latinoamericanas, norteamericanas y caribeñas.

Durante todas estas formaciones nacionales la palabra escrita e impresa toma un rol protagónico. El libro es fundamental para que estas sociedades del nuevo mundo capturen su historia, leyes, ciencia y literatura. Las imprentas de los gobiernos y privadas comienzan a plasmar la identidad de cada pueblo y permiten la circulación de su producción literaria. Según cada país desarrolla e implanta sus proyectos de educación para erradicar el analfabetismo, los mercados de la palabra crecen y resultan en la creación de archivos, bibliotecas y librerías en todos los centros regionales y en manos privadas. La educación lleva a la formación de varios cánones literarios, exponiendo a nuevas generaciones a obras consideradas importantes para cada pueblo. Esta práctica, llevada a cabo por varios siglos, lleva a la cristalización de las literaturas nacionales. La circulación de las mismas por rutas mercantiles, y su estudio a nivel universitario, nos lleva a la conceptualización de la literatura latinoamericana (incluyendo la caribeña hispanoparlante) con unos elementos básicos en común: ataduras históricas a una colonización del continente americano por España y Portugal, un historial de luchas para la independencia de los pueblos formados por esa colonización y unas literaturas que surgen regionalmente y en conversaciones entre sus figuras principales.

Cuando llegamos a mediados del siglo XX ya hay mercados enormes de creación, publicación y circulación de literatura en cada país y por cada idioma, incluyendo la industria de la traducción. Aunque las tecnologías del cine, radio y televisión han derivado en industrias y medios poderosos para la comunicación, ninguna ha amenazado las industrias del material impreso (libros, revistas, periódicos). A comienzos de siglo XXI entran en juego una serie de tecnologías electrónicas y digitales que a un paso cada vez más acelerado buscan suplantar al libro impreso como el medio principal para la circulación de la palabra. Las redes digitales y los libros electrónicos tienen un gran impacto sobre las industrias de la imprenta porque permiten la comunicación eficaz de la palabra a la vez que la integran con imágenes, video y/o sonido para producir comunicación multimodal en las redes. Con la miniaturización y costos cada vez más baratos de equipos digitales para la circulación de la palabra, como los lectores de libros electrónicos producidos por compañías multinacionales como Amazon, la industria del libro se ve amenazada. Las casas publicadoras y librerías, dependiendo por país y región, ven sus ventas mermar y se han ido adaptando a nuevos modelos como la impresión por pedido, a producciones tanto electrónicas como en papel y accesos a contenido publicado mediante suscripciones, entre otros. El mundo del libro y los modelos de publicación y distribución son cada vez más digitales y globales, cruzando fronteras a una velocidad mucho más acelerada que las rutas mercantiles terrestres, marítimas y aéreas necesarias para la circulación de la palabra mediante objetos físicos.

36 La era digital, particularmente alrededor del lanzamiento de la Web en 1995 ha revolucionado las comunicaciones a nivel global. Un mensaje de correo electrónico puede darle la vuelta al mundo en segundos. Una imagen o video puede convertirse en un fenómeno viral y alcanzar billones de vistas. Las redes de artistas y académicos interesados en la literatura electrónica ignoran las fronteras para llegar a donde haya interés y acceso a los medios digitales. En una era de globalización acelerada, ¿Se puede distinguir la literatura electrónica estadounidense, latinoamericana, caribeña de la europea? ¿Qué tal de la asiática, rusa, australiana, africana, india, escandinava, o del Medio Oriente? 
37 Los artistas y académicos sin comunidades afines a sus intereses pueden conectarse fácilmente con otros. Los residentes de un país que aún se encuentre en la primera o segunda fase de adopción de literatura electrónica pueden simplemente conectarse con organizaciones e iniciativas en otros países que transitan otras etapas. A fin de cuentas, nos une el interés por el potencial de las tecnologías digitales para presentar la palabra.

Es por esto que considero que la literatura electrónica es electrónica antes de ser caribeña o latinoamericana, aunque sin negar los temas y tradiciones culturales que han formado al autor.

\section{BIBLIOGRAFÍA}

BUSH, V. (1945). “As we may think”. The atlantic monthly, 176(1), 101-108.

FLORES, Leonardo (2016). “Géneros literarios digitales: primera parte”. 80 Grados. Disponible en http://www.80grados.net/generos-literarios-digitales-primera-parte/

FLORES, Leonardo (2017). “Géneros literarios digitales: segunda parte”. 80 Grados. Disponible en http://www.80grados.net/generos-literarios-digitales-segunda-parte/

FUNKHOUSER, C. T. (2007). Prehistoric digital poetry: an archaeology of forms, 1959-1995. The University of Alabama Press.

HAYLES, N. K. (2004). "Print is flat, code is deep: The importance of media-specific analysis". Poetics Today, 25(1), 67-90.

KING, Rosamond (2017). "Statement on Digital Literature". SX Salon, 25. Disponible en http:// smallaxe.net/sxsalon/poetry-prose/statement-digital-literature.

ONG, W. J. (2013). Orality and literacy. Routledge.

URIBE, Ana María (1997). Tipoemas y Anipoemas. Electronic Literature Collection, Volúmen 3. Disponible en http://collection.eliterature.org/3/work.html?work=tipoemas-y-anipoemas.

\section{RESÚMENES}

En este ensayo cuestiono narrativas de tradiciones literarias nacionales y regionales cuando se refieren a la literatura electrónica con el fin de mostrar cómo la misma está atada primordialmente a tecnologías digitales e influencias internacionales. Para contextualizar esto, expando el modelo de N. Katherine Hayles de generaciones de desarrollo de la literatura electrónica al añadir una tercera fase que aplica al momento actual tecnológico. Describo, además, cuatro fases de adopción de la literatura electrónica: (1) acercamiento, (2) descubrimiento, (3) desarrollo y (4) adopción situando ejemplos de literatura electrónica latinoamericana y caribeña dentro del modelo. Concluyo con una narrativa histórica de las tecnologías literarias y el rol que tienen en el desarrollo de literaturas nacionales y regionales, regresando al cuestionamiento inicial. 
Dans ce travail, je questionne des récits de traditions littéraires nationales et régionales en me référant à la littérature électronique, afin de montrer comment elle est liée principalement aux technologies numériques et aux influences internationales. Ainsi j'élargis le modèle de $\mathrm{N}$. Katherine Hayles traitant des étapes du développement de la littérature électronique en ajoutant une troisième phase : le moment technologique actuel. Je décris également quatre phases d'adoption de la littérature électronique: 1) Approche (2) découverte (3) Développement (4) Adoption. Pour ce faire, j'utilise des exemples de littérature électronique d'Amérique latine et des Caraïbes. Je termine par un récit historique des technologies littéraires et du rôle qu'elles jouent dans le développement des littératures nationales et régionales.

ÍNDICE

Mots-clés: littérature électronique, littérature numérique, technologies d'écriture, littérature latino-américaine, littérature antillaise, culture numérique

Palabras claves: literatura electrónica, literatura digital, tecnologías de escritura, literatura latinoamericana, literatura caribeña, alfabetización digital

\section{AUTOR}

\section{LEONARDO FLORES}

Catedrático.

Departamento de Inglés. Universidad de Puerto Rico: Mayagüez. leonardo.flores(at)upr.edu 